\title{
Health improvement through the teeth and oral health awareness and care of teeth and mouth in children for Panti Guna SLB Melati Aisyiyah Desa Bandar Khalifah
}

\author{
Dewi Kartika $^{1 *}$, Trelia Boel ${ }^{1}$, Cek Dara Manja ${ }^{1}$, Lidya Irani Nainggolan ${ }^{1}$, Fitri Yunita \\ Batubara $^{1}$ \\ ${ }^{1}$ Faculty of Dentistry, Universitas Sumatera Utara \\ *Email: dewi.kartika@usu.ac.id
}

\begin{abstract}
Health is very important to always pay attention to. Healthy behavior can affect the health of everybody. Dental and oral health is a part of general health, and to keep teeth and mouth healthy can be done with the right techniques and ways to brush teeth. Based on Basic Health Research, dental and oral diseases still occur in North Sumatra province, both urban and rural. Therefore, through the Community Service Institution at USU, a community service activity was carried out under the title Improvement of Dental and Mouth Health through the Counseling for Dental and Oral Health Care for Children of Melati Aisyiah SLB Orphanage Homes in Bandar Khalifah. This activity is based on the need to maintain oral health from an early age so that good behavior in maintaining health can be accustomed from childhood. In addition, there are only a few orphanage children who realize correctly the importance of dental health for general health. Counseling on the maintenance of dental and oral health in children of the SLB Melati Aisyiyah Orphanage, Bandar Khalifah can provide a deep understanding of the importance of maintaining oral health by brushing teeth early on.
\end{abstract}

Keywords: Health, dental and oral health, brush teeth, children

\begin{abstract}
Abstrak
Kesehatan sangat penting untuk selalu diperhatikan. Perilaku sehat dapat memengaruhi kesehatan setiap orang. Kesehatan gigi dan mulut adalah bagian dari kesehatan umum, dan untuk menjaga kesehatan gigi dan mulut dapat dilakukan dengan teknik dan cara menyikat gigi yang tepat. Berdasarkan Riset Kesehatan Dasar, penyakit gigi dan mulut masih terjadi di provinsi Sumatera Utara, baik perkotaan maupun pedesaan. Oleh karena itu, melalui Lembaga Layanan Masyarakat di USU, kegiatan pelayanan masyarakat dilakukan dengan judul Peningkatan Kesehatan Gigi dan Mulut melalui Konseling untuk Perawatan Kesehatan Gigi dan Mulut untuk Anak-anak Rumah Panti Asuhan SLB Melati Aisyiah di Panti Asuhan SLB di Bandar Khalifah. Kegiatan ini didasarkan pada perlunya menjaga kesehatan mulut sejak usia dini sehingga perilaku yang baik dalam menjaga kesehatan dapat dibiasakan sejak kecil. Selain itu, hanya ada beberapa anak yatim piatu yang menyadari dengan benar pentingnya kesehatan gigi untuk kesehatan umum. Konseling tentang pemeliharaan kesehatan gigi dan mulut pada anak-anak di Panti Asuhan SLB Melati Aisyiyah, Bandar Khalifah dapat memberikan pemahaman yang mendalam tentang pentingnya menjaga kesehatan mulut dengan menyikat gigi sejak dini.
\end{abstract}

Kata kunci: Kesehatan, kesehatan gigi dan mulut, sikat gigi, anak-anak

\section{PENDAhuluan}

Menurut WHO, kesehatan gigi dan mulut merupakan bagian yang sangat penting dari kesehatan secara umum dan berpengaruh terhadap kesejahteraan. Kesehatan gigi dan mulut yang buruk dapat mengakibatkan terganggunya kualitas hidup (Jürgensen and Petersen, 2009).Oleh sebab itu, sangat penting menjaga rongga mulut dan gigi agar senantiasa selalu sehat dengan selalu menjaga kebersihannya (Bangash et al., 2012). Rongga mulut dan gigi yang bersih membuat orang merasa lebih percaya diri untuk berbicara, makan, dan bersosialisasi tanpa rasa sakit, tidak nyaman ataupun rasa malu (Kwan et al., 2005). 
Dewi Kartika et.al Health improvement through the teeth

Tindakan pencegahan yang paling utama agar gigi tidak rusak adalah dengan menjaga kebersihan gigi dan mulut setiap hari dengan benar.Agar kebersihan gigi dan mulut dapat selalu terjaga dengan baik, maka tindakan yang paling banyak dianjurkan dan dilaksanakan adalah menyikat gigi (Asadoorina, 2006). Menyikat gigi secara teratur merupakan metode utama untuk menghilangkan plak serta mengontrol penyakit akibat plak, seperti karies dan periodontitis (Gallagher, 2009).

Perilaku menggosok gigi pada anak harus dilakukan dalam kehidupan sehari-hari tanpa ada perasaan terpaksa. Kemampuan menggosok gigi secara baik dan benar merupakan faktor yang cukup penting untuk perawatan kesehatan gigi dan mulut. Keberhasilan menggosok gigi juga dipengaruhi oleh faktor penggunaan alat, metode menggosok gigi, serta frekuensi dan waktu menggosok gigi yang tepat (Arianto dkk, 2014)

Hasil Riskesdas 2013 tentang kesehatan gigi dan mulut yaitu prevalensi nasional masalah gigi dan mulut adalah 25,9 persen, sebanyak 14 provinsi mempunyai prevalensi masalah gigi dan mulut diatas angka nasional. Prevalensi nasional menyikat gigi setiap hari adalah 94,2 persen sebanyak 15 provinsi berada dibawah prevalensi nasional. Untuk perilaku benar dalam menyikat gigi berkaitan dengan faktor gender, ekonomi, dan daerah tempat tinggal. Ditemukan sebagian besar penduduk Indonesia menyikat gigi pada saat mandi pagi maupun mandi sore, $(76,6 \%)$. Menyikat gigi dengan benar adalah setelah makan pagi dan sebelum tidur malam, untuk Indonesia ditemukan hanya 2,3 persen ( Riskesdas 2013).

Prevalensi masalah gigi dan mulut di Sumatera Utara sebesar 19,4\%. Saat umur sudah lebih dari satu tahun dimana gigi geligi mulai tumbuh, maka persentase masalah gigi dan mulut terus meningkat. Penyakit gigi dan mulut dapat terjadi baik di perkotaan maupun di pedesaan, dengan prevalensi sebesar $26 \%$ dan 25,9\%. Perbedaan tersebut tidak begitu jauh.Di perkotaan, ketersediaan dokter gigi lebih besar dibandingkan di pedesaan, sehingga perawatan gigi di perkotaan lebih baik dibandingkan pedesaan.Oleh sebab itu sangat penting dilakukan pencegahan sedini mungkin agar terhindar dari masalah penyakit gigi dan mulut (Riskesdas 2013).

Pentingnya pendidikan terkait menjaga kesehatan gigi dan mulut yang dilakukan secara terus menerus memberikan hasil yang baik.Pencegahan serta promosi kesehatan gigi dan mulut harus dilakukan sedini mungkin untuk mencegah timbulnya masalah gigi dan mulut (Deljo et al., 2011). Kebiasaan dan gaya hidup yang dikembangkan saat usia muda akan lebih melekat karena pesan - pesan yang diperoleh dapat semakin diperkuat selama mereka masih dalam masa sekolah (Kwan et al., 2005).

\section{METODE PELAKSANAAN}

Kegiatan pengabdian pada masyarakat yang berjudul Peningkatan Kesehatan Gigi dan Mulut Melalui Penyuluhan Pemeliharaan Kesehatan Gigi dan Mulut Pada Anak-Anak Panti Guna SLB Melati Aisyiah Desa Bandar Khalifah diawali dengan kata sambutan dari Ketua Yayasan dan Ketua Panti Guna SLB Melati Aisyiah Desa Bandar Khalifah, Ketua Program Pengabdian kepada Masyarakat dilanjutkan dengan ceramah dan penyuluhan kepada anak-anak. Ceramah dilakukan dengan media audiovisual.

Kegiatan penyuluhan dibantu oleh mahasiswa dengan memperagakan cara menyikat gigi di phantom gigi dengan teknik Bass dengan metode penyikatan gigi yang dimulai dari rahang bawah sebelah kiri, depan dan kanan bagian dalam, lalu pada rahang atas sebelah kanan, depan dan kiri bagian dalam. Kemudian dilanjutkan pada rahang atas kiri, depan dan kanan bagian luar, lalu pada rahang bawah sebelah kanan, depan dan kiri bagian luar. Seluruh permukaan gigi harus disikat juga termasuk permukaan lidah.

Kegiatan pengabdian ini dilaksanakan dalam dua tahap, yaitu tahap penjelasan dan pengujian awal, dan tahap pelatihan dan evaluasi

a) Penjelasan dan Pengujian Awal

1. Dilakukan oleh 1 orang anggota Tim Pengabdian bersama 2 orang mahasiswa 
2. Tim pengabdian akan melakukan penyuluhan, menjelaskan pentingnya pemeliharaan kesehatan gigi sebagai upaya menjaga kesehatan gigi dan mulut melalui audiovisual dan phantom gigi

3. Perwakilan orangtua panti asuhan diminta untuk mengulangi dan menjelaskan cara dan waktu menyikat gigi yang benar dan tepat. Hal ini dilakukan untuk mendapatkan umpan balik apakah sudah dapat menjadi sumber informasi untuk anak panti asuhan.

b) Pelatihan dan evaluasi

Setelah dilakukan penjelasan dan pengujian awal, tahap selanjutnya adalah pelatihan cara menyikat gigi yang benar.

1. Tim pengabdian dibagi menjadi 5 kelompok. Setiap kelompok dibantu oleh 4 orang mahasiswa.

2. Masing-masing anak diberikan sikat gigi dan pasta gigi.

3. Penyikatan gigi dilakukan bersama-sama pada phantom gigi sesuai dengan instruksi sebelumnya, sambil memperhatikan apabila ada anak yang salah dalam menyikat giginya.

4. Setelah anak-anak selesai menyikat gigi, kemudian dilakukan evaluasi kembali apabila masih ada beberapa kesalahan teknik menyikat gigi yang terjadi saat anak-anak tadi menyikat gigi.

5. Memberitahu kembali cara menyikat gigi yang benar dengan menggunakan phantom gigi

\section{HASIL DAN PEMBAHASAN}

Program pengabdian kepada masyarakat dosen mengabdi dilakukan di Panti Guna SLB Melati Aisyiyah di Jalan Mesjid No 806 Pasar IX Tembung, Desa Bandar Khalifah. Kegiatan dimulai dari penyuluhan sampai cara menyikat gigi bersama dan evaluasi kembali. Kegiatan ini diawali dengan pembukaan oleh tim penyuluh, kemudian dilanjutkan dengan kata sambutan dari pihak Panti Guna SLB Melati Aisyiyah.

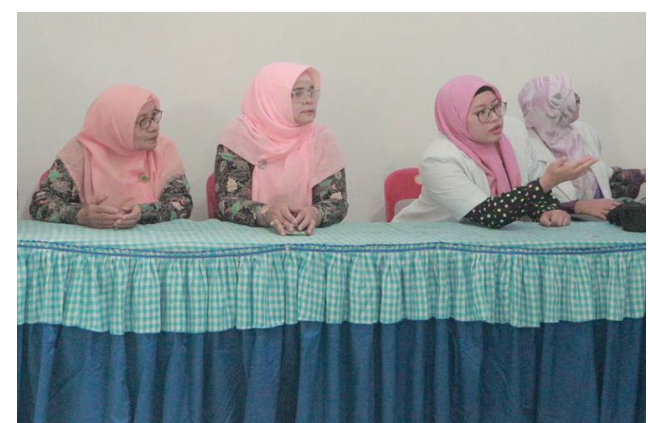

Gambar 3.1. Pembukaan oleh Tim Penyuluh

Acara kemudian dilanjutkan dengan penyampaian materi penyuluhan yang disampaikan oleh pemateri. Pada saat penyampaian materi digunakan metode ceramah, dibantu dengan slide dan phantom gigi, diputarkan juga video yang berkaitan dengan cara menyikat gigi. 


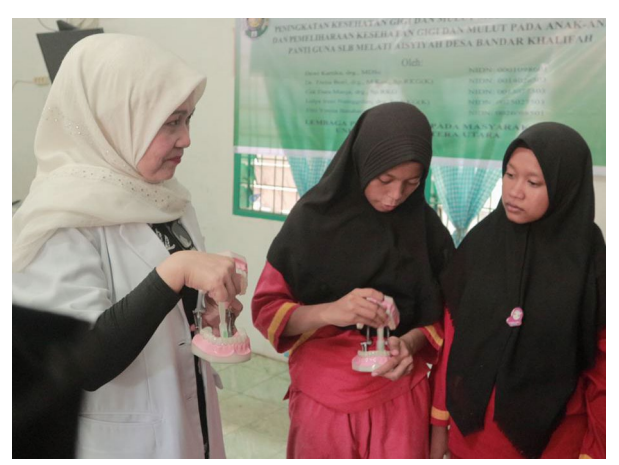

Gambar 3.2. Penyuluhan disampaikan Pemateri

Selanjutnya dilakukan penyikatan gigi bersama dengan anak-anak dari Panti Guna SLB Melati Aisyiyah.

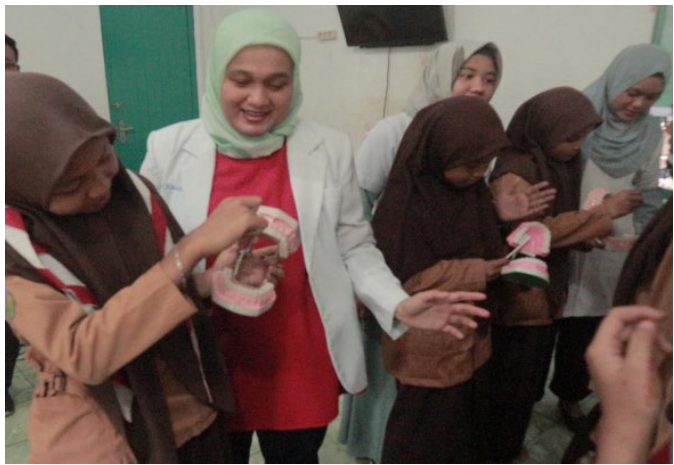

Gambar 3.3. Penyikatan gigi bersama anak- anak Panti Guna SLB Melati Aisyiyah

Dalam kegiatan ini terlihat anak-anak sangat antusias terhadap kegiatan yang dilakukan. Tanpa rasa takut mereka mau mengikuti arahan dan mencoba memperbaiki cara menyikat giginya. Hasilnya terdapat perubahan cara menyikat gigi yang baik setelah diberikan penyuluhan dan pelatihan dibandingkan sebelum dilakukan penyuluhan dan pelatihan cara menyikat gigi. Sesi terakhir ditutup dengan Tanya jawab dan foto bersama.

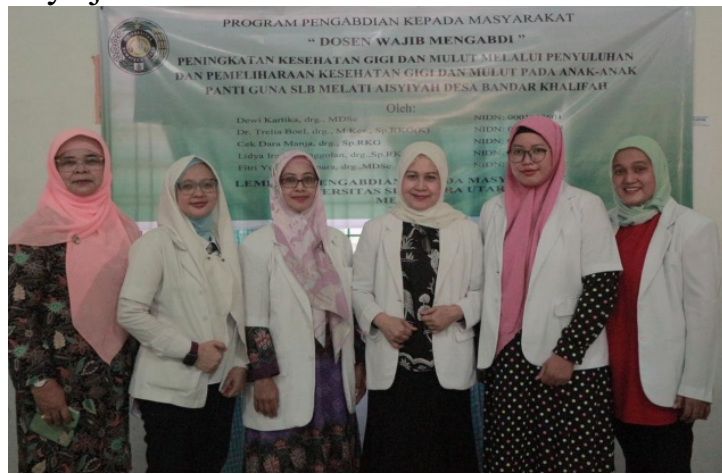

Gambar 3.4. Foto Bersama dengan Pengurus Yayasan 


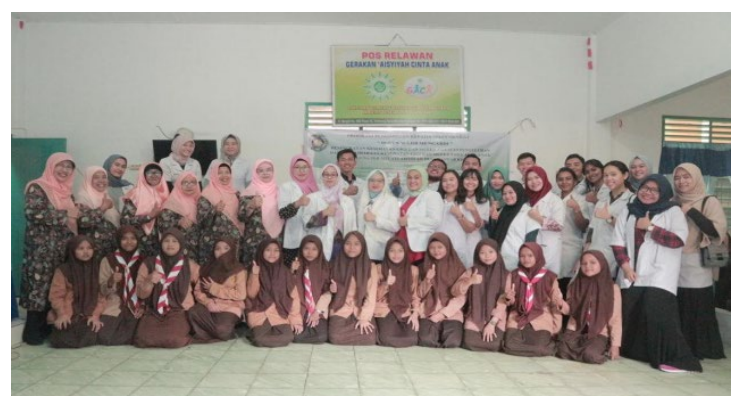

Gambar 3.5. Foto Bersama dengan Anak-Anak yang Mengikuti Kegiatan Penyuluhan

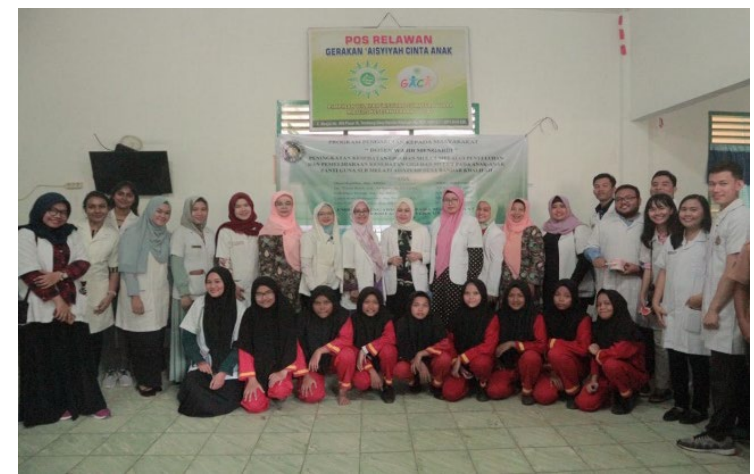

Gambar 3.6. Foto Bersama dengan Anak-Anak SMP Panti Guna SLB Melati Aisyiyah

\section{KESIMPULAN}

Penyuluhan tentang pemeliharaan kesehatan gigi dan mulut pada anak-anak Panti Guna SLB Melati Aisyiyah Desa Bandar Khalifah dapat memberikan pemahaman yang mendalam tentang pentingnya menjaga kesehatan gigi dan mulut dengan cara menyikat gigi sejak dini. Hal ini dibuktikan dengan kemampuan anak-anak untuk mengikuti dan mengaplikasikan cara menyikat gigi yang benar sesuai dengan apa yang telah diajarkan oleh pemateri.

\section{UCAPAN TERIMA KASIH}

Artikel ini merupakan salah satu hasil dari Program Pengabdian kepada Masyarakat yang dibiayai oleh Lembaga Pengabdian Kepada Msyarakat Universitas Sumatera Utara tahun 2019 Skema Dosen Mengabdi. Oleh karena itu, diucapkan terima kasih kepada Rektor Universitas Sumatera Utara atas dukungan dana dan fasilitas yang diberikan. Terima kasih juga kepada Mitra pada kegiatan pengabdian ini.

Artikel ini merupakan salah satu hasil dari Program Pengabdian kepada Masyarakat Sumber Dana Non PNPB Universitas Sumatera Utara Sesuai dengan Surat Perjanjian Penugasan Pelaksanaan Program Pengabdian kepada Masyarakat Skim Dosen Mengabdi Tahun Anggaran 2019 Nomor: 785/ UN5.2.3.2.1/ PPM /2019, Tanggal 23 Juli 2019.

\section{DAFTAR PUSTAKA}

Arianto, Shaluhiyah, Z, Nugraha, P,. Perilaku menggosok gigi pada siswa sekolah dasar kelas 5 dan 6 di kecamatan Sumberejo. Jurnal promosi kesehatan Indonesia, 9(2): 127-35.

Asadoorina, J., (2006), Tooth Brushing, Canadian Journal of Dental Hygiene (CDJH), 40(5): 1-14. 
Bangash, R.Y., Khan, A. U., Tariq, K. M., and Dil, R., (2012), Evaluation of Tooth Brushing Technique and Oral Hygiene Knowledge at Afid, Rawalpindi, Pakistan Oral and Dental Journal, 32(1): 124-27.

Deljo, E., Barbacic, R., Meskovic, B., and Grabus, J., (2011), Impact of Continous Education About Oral Hygiene on the Changes of CPI-Index for 12-15 years old School Children, Acta Inform med, 19(4): 220-23.

Departemen Kesehatan Republik Indonesia, Data Laporan Nasional Riset Kesehatan Dasar, 2013.

Gallagher, A., Sowinski, J., Bowman, J., Barrett, K., Lowe, S., Patel, K., Bosma, M.L., and Creeth, J. E., 2009, The Effect of Brushing Time and Dentifrice on Dental Plaque Removal Invivo. The Journal of Dental Hyegiene, 83(3): 111-16.

Jügensen, N., and Petersen, P.E., (2009), Oral Health and the Impact of Socio Behavioral factors in a Cross Sectional Survey of 12-year old School Children in Laos, Biomed Central Oral Health, 9(29): 1-11.

Kwan, S.Y.L., Petersen, P.E., Pine, C.M., and Borutta, A., (2005), Health Promoting Schools: an Opportunity for Oral Health Promotion, Bulletin of the World Health Organization, 83(9): 677-85. 